\title{
AC 2008-1234: THE EFFECT OF COOPERATIVE EDUCATION ON SELF-EFFICACY AMONG UNDERGRADUATE ENGINEERING STUDENTS
}

Joe Raelin, Northeastern University

Jerry Hamann, University of Wyoming

David Whitman, University of Wyoming

Rachelle Reisberg, Northeastern University 


\title{
The Effect of Cooperative Education on Self-Efficacy among Undergraduate Engineering Students
}

\begin{abstract}
Northeastern University (NU) and the University of Wyoming (UW) are investigating whether the participation of sophomores (with particular attention to women) in formal undergraduate engineering programs that provide work experiences while enrolled (e.g., cooperative education and internships) is related to enhanced self-efficacy. Self-efficacy theory provides an important framework for differentiating the career outcomes of students in engineering. In particular, positive self-efficacy beliefs appear to significantly affect persistence in undergraduate engineering programs. This study found that co-op programs appear to make a significant contribution to the enhancement of work selfefficacy.
\end{abstract}

\section{Purpose}

The purpose of this study is to isolate those factors that contribute most to the development of three self-efficacy dimensions thought to be most relevant to the retention of sophomores (especially women) in undergraduate engineering: work, academic, and career. It examines, in particular, if cooperative education alone enhances efficacy (while controlling for pre-existing conditions among students enrolling in a cooperative education school as well as controlling for alternative supports for students to assist them during their undergraduate experience). One of the schools participating in the study, Northeastern University, requires cooperative (co-op) education whereas the University of Wyoming does not.

The critical research questions addressed are:

1. Are formal co-op experiences positively associated with three of the critical dimensions of selfefficacy: work, academic, and career?

2. What are the relationships among demographic characteristics, cooperative education, contextual supports, and work, academic, and career self-efficacy?

This paper presents the methodology and previously unpublished summary findings from a longitudinal study of workplace learning, conducted at both Northeastern University and the University of Wyoming. The background and methodology given below were originally presented in a preliminary form at the $37^{\text {th }}$ ASEE/IEEE Frontiers in Education Conference ${ }^{1}$ as a work in progress and are included here, in addition to the findings, to provide a context for the reader.

\section{Background}

Colleges and universities around the country are placing a growing emphasis on programs that allow students to gain work experience and are beginning to define success by more than just academic learning. These programs comprise co-op jobs, internships, apprenticeships, and other methods that integrate experience in the world with experience in the classroom. These 
approaches are becoming increasingly relevant in a work culture characterized by the need to continuously reflect and learn from ongoing experience. ${ }^{2}$ A 1998 census of cooperative education found that approximately 250,000 U.S. students were placed in cooperative education jobs that year. ${ }^{3}$ In 2006, the career publisher Vault.com. reported in its third Internship Survey that some $62 \%$ of undergraduate students completed an internship that year. ${ }^{4}$

In terms of outcome studies from co-op, the majority of research was conducted in the 1970's and 1980's due to the influx of federal funding to these programs. There have been fewer contributions since that time. Overall, co-op research has revealed positive outcomes along five categories of performance: economic benefits, academic benefits, career development, initial employment, and personal growth. ${ }^{5,6,7}$

One promising avenue that has been used to tie work-based processes to outcomes is Albert Bandura's concept of self-efficacy. ${ }^{8}$ Self-efficacy is defined as an individual's perceived level of competence or degree to which an individual believes he/she is capable of completing a task. Self-efficacy is a dynamic trait that changes over time and can be influenced by experience. Self-efficacy expectations are considered the primary cognitive determinant of whether or not an individual will attempt a given behavior. Bandura ${ }^{9}$ identified four sources of information that shape self-efficacy: (1) performance accomplishments, (2) vicarious experience, (3) verbal persuasion, and (4) physiological and affective states.

Fletcher ${ }^{10}$ provided a theoretical framework to explain how cooperative education experiences enhance self-efficacy and help students make the transition from student to practitioner. Specifically, Fletcher suggested that cooperative education increases self-efficacy through performance accomplishments. In this case, performance accomplishments would be co-op experiences whereby individuals use skills, abilities, and coping strategies to perform tasks. Successful experiences can result in a feedback loop where performance accomplishments lead to increased self-efficacy, which in turn, enhances a person's performance, further strengthening self-efficacy beliefs. The possibility that cooperative education can be a source of efficacy information through performance accomplishments is provocative, given that such accomplishments are generally viewed as the most potent source of self-efficacy information; that is, of the four sources of efficacy information, performance accomplishments are thought to exert the most influence. ${ }^{11}$ Workplace experience may also expose students to successful peer models, mentor figures, and verbal encouragement that can provide self-efficacy information through Bandura's vicarious experiences and verbal persuasion sources. To date, however, research has not explicitly examined the effect of undergraduate cooperative education and internship experiences on self-efficacy beliefs.

Turning to the gender literature, women have been and continue to be underrepresented in engineering, receiving only $17.7 \%$ of bachelor's degrees in engineering ${ }^{12}$ and holding only $11 \%$ of engineering positions. ${ }^{13}$ Although they are as academically prepared and academically successful as men, they can lag behind men by exhibiting lower levels of academic satisfaction and lack of self-esteem. ${ }^{14}$

Traditional assumptions about career options for women have been reinforced in society and have projected stereotypes that discourage talented women from continuing in engineering 
careers. This is evidenced by research that has found a dramatic drop in women's self-efficacy throughout the course of engineering programs. In an in-depth study of students who switched out of science, math, and engineering majors, $77.9 \%$ of women cited discouragement and loss of self-esteem as a factor in switching. ${ }^{15}$

Hackett and Betz ${ }^{16}$ were the first to use self-efficacy to explain the career development of women, especially in male-dominated career domains. They suggested that societal factors have created gender differences in gaining access to primary sources of self-efficacy information in male-dominated career fields. In turn, lower self-efficacy beliefs about these careers have resulted in fewer women entering these fields. Since then, empirical studies have supported this theory, finding that college-aged women's self-efficacy for traditionally female occupations was significantly higher than their self-efficacy within male-dominated fields. ${ }^{17,18}$

\section{Conceptual Framework}

This study seeks to develop a theory that examines the effects cooperative education as well as other factors (demographics, contextual supports) have on self-efficacy beliefs. It includes wellestablished measures of science/ math/ engineering academic self-efficacy and of career selfefficacy while introducing a new construct, work self-efficacy. Figure 1 displays the conceptual framework for the study, depicting the relationships among demographic characteristics, cooperative education, contextual supports, and work, academic, and career self-efficacy.

The goal is to isolate those factors that contribute most to the development of the three selfefficacy dimensions and determine if cooperative education alone enhances efficacy controlling for pre-existing conditions among students enrolled in a cooperative education school as well as controlling for alternative supports for students to assist them during their undergraduate experience.

Three dimensions of self-efficacy have been chosen because they are thought to be most linked to the retention of students in undergraduate engineering. Specifically, work self-efficacy measures the confidence that students have in managing workplace experiences; academic selfefficacy measures their confidence in handling an academic workload and succeeding in college; and career self-efficacy measures their confidence in establishing a successful career in the engineering field. Work self-efficacy was thought to be relevant to non-co-op students because most students in undergraduate engineering programs have some form of work experience. Career self-efficacy was thought to be differentiable because it refers to one's confidence in preparing oneself for a career (e.g., in assessing self or in deploying occupational information) rather than in managing oneself in the workplace. 


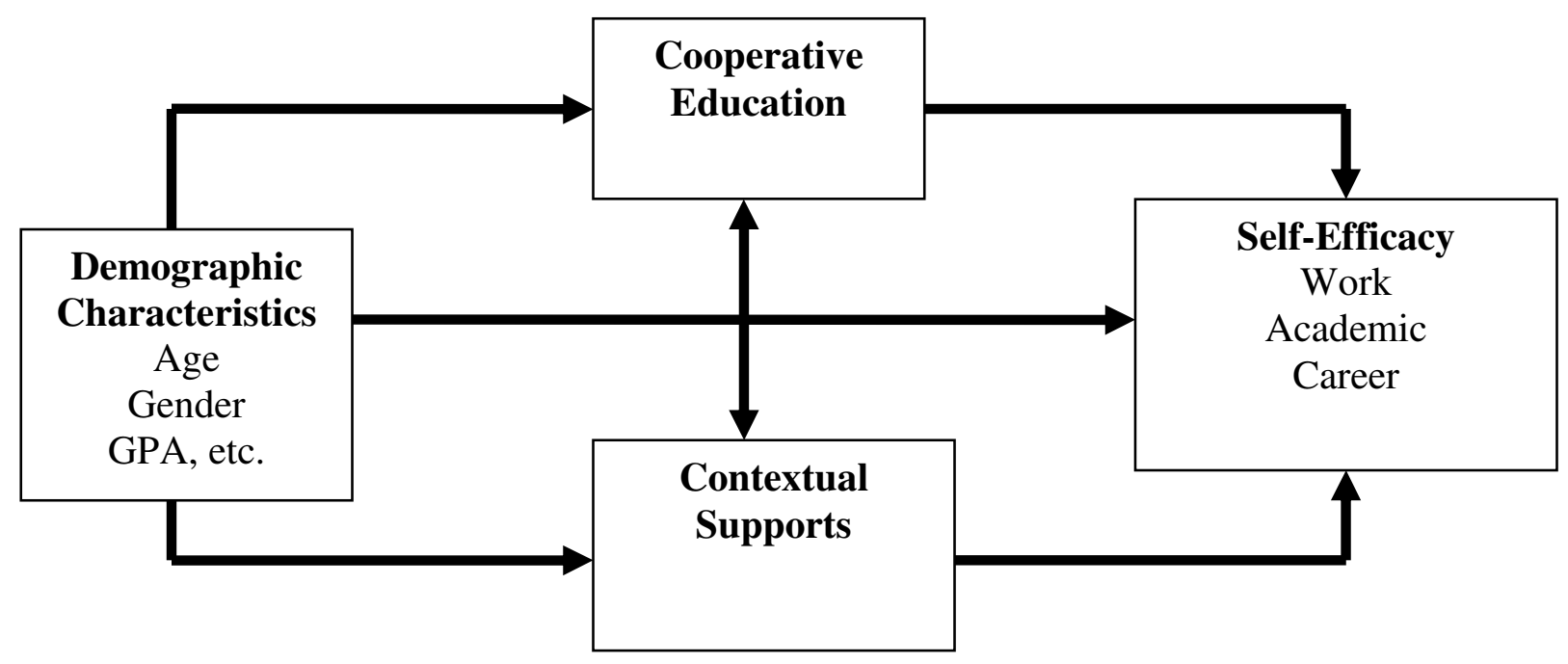

Figure 1

RELATIONSHIP AMONG THE STUDY's PRINCIPAL VARIABLES

\section{Methodology}

The measures of the principal study variables are as follows. The new work self-efficacy inventory (WS-Ei), developed at the Center for Work and Learning at Northeastern University, measures a range of behaviors and practices that relate to the non-technical and social skills necessary to achieve success in the workplace. The inventory features seven subscales: problem-solving, sensitivity, communication, teamwork, learning, pressure, and politics. Academic self-efficacy was derived from the Self-Efficacy for Academic Milestones and SelfEfficacy for Technical/Scientific Fields surveys, ${ }^{19}$ and career self-efficacy was obtained directly from the short-form of the Career Decision-Making Self-Efficacy Scale of Betz, Klein, and Taylor. ${ }^{20}$ Among the contextual control variables, the social support measure was derived from the contextual supports subscales of Lent et al., ${ }^{21}$ and from the rapport and apprenticeship subscales of the Advisory Working Alliance Inventory (AWAI) prepared by Schlosser and Gelso. $^{22}$ The survey instrument obtained the remaining demographic and work experience data directly from the respondents.

A pre-and post-survey was distributed to all students in the sophomore engineering classes at both sites. At Northeastern University (NU), the first survey was distributed in required co-op preparation courses in November of 2005 prior to the students' first six-month co-op assignment. Students completed their post-surveys upon return to campus in required core courses. At the University of Wyoming (UW), the first survey was also distributed in November of 2005 to all sophomores, either in their required core courses or on-line as needed. The post-survey was distributed one year later in November of 2006 in required major classes and through on-line communication. 
Since the individual student is the unit of analysis, the study tracked student respondents using ID codes. The number of respondents in NU's co-op sample was 194, and there were 92 in the UW's non-co-op sample. These represent $49 \%$ and $41 \%$ of the sophomore engineering classes respectively at the two universities. The number of women in the total pre-survey sample was 50 or $17 \%$ of the total.

For the post-survey, at NU, the number of respondents was 78, representing a fairly modest $40 \%$ follow-up response rate. At UW, the number of post-survey respondents was 72, representing a robust $78 \%$ follow-up response rate.

In order to address the first research question [Are formal co-op experiences positively associated with three of the critical dimensions of self-efficacy: work, academic, and career], paired sample t-tests were conducted, comparing the change in measures of self-efficacy among students in the traditional vs. cooperative education programs. The change scores were computed as the difference in ratings for the three self-efficacy scales given by student respondents at the pre-survey stage compared to the post-survey stage.

In order to address the second research question [What are the relationships among demographic characteristics, contextual supports, cooperative education, and work, academic, and career selfefficacy], a multiple regression was fit for each of the self-efficacy outcomes. In particular, a general linear model (GLM) least squares analysis was run to determine the extent to which the dependent variable scales - the three efficacy changes scores - can be explained by a combination of the remaining discrete or continuous independent variables in addition to or apart from co-op participation.

\section{Results}

Scale Validation: Each of the three self-efficacy scales as well as the subscales in the work selfefficacy (W-SE) and career self-efficacy (C-SE) scales produced high reliabilities, measured by Cronbach's alpha coefficient of internal consistency:

W-SE: 95

C-SE: .94

A-SE (academic): .92

These general scales and all the embedded subscales are above the recommended .70. The advisor and mentor scales also performed well: Advisor at .93 and Mentor at .96. A factor analysis on the scale data essentially reproduced the four scales (the Mentor scale was not factoranalyzed because of the low number of cases).

The three major self-efficacy scales were found to have a high degree of concurrent validity, measured initially by correlations that were high and significant but not so high as to be equivalent, thus (at the pre-survey period):

$\mathrm{W}-\mathrm{SE}$ and $\mathrm{C}-\mathrm{SE}=.64$

$\mathrm{A}-\mathrm{SE}$ and $\mathrm{C}-\mathrm{SE}=.48$

$\mathrm{W}-\mathrm{SE}$ and $\mathrm{A}-\mathrm{SE}=.34$ 
Compatible inter-correlations were reproduced at the post-survey period.

The Effect of Co-op on Efficacy: Before determining whether co-op effected a change in efficacy, we first had to determine whether there was a significant change in efficacy to begin with. A t-test found that for the total sample, there was a significant change between the two periods for work and career self-efficacy, but not for academic self-efficacy:

$\begin{array}{llll} & \text { Mean } & \mathrm{t} & \text { Significance } \\ \text { Work self-efficacy change } & .167 & 3.88 & .01 \\ \text { Career self-efficacy change } & .142 & 3.11 & .01 \\ \text { Academic self-efficacy change } & .078 & 1.44 & .15 \text { (not sig) }\end{array}$

A second set of t-tests were then performed to determine whether the two samples (NU as a coop school and UW as a non-co-op school) differed on these three change scores. The following results were produced:

$\begin{array}{lllll} & \text { NU mean } & \text { UW mean } & \mathrm{t} & \text { Significance } \\ & & & & \\ \text { Work self-efficacy change } & .229 & .099 & 2.29 & .03 \\ \text { Career self-efficacy change } & .117 & .171 & -.84 & .40 \text { (not sig) } \\ \text { Academic self-efficacy change } & -.016 & .181 & -2.74 & .01\end{array}$

These findings disclose that NU students on co-op increased their work self-efficacy significantly more than UW students, whereas UW students (not on co-op) significantly increased their academic self-efficacy compared to NU students.

The Additive Effect of the Control Variables: When controlling for demographic and contextual support variables, advisor support was a critical predictor of efficacy of all types at the post-survey period. Prior academic achievement, as would be expected, predicted academic self-efficacy at the post-survey period. Non-minority students and students from higher socioeconomic classes were most likely to increase their efficacy scores over the measured period, and women (17\% of respondents) were found to be more confident in obtaining occupational information and learning from their work. Finally, work experiences other than coop, such as summer jobs and internships, when connected to the student's major were found to have isolated positive effects on work self-efficacy and career self-efficacy subscores.

\section{Conclusions}

This paper describes a pilot study that addresses the question whether co-op programs contribute to enhanced self-efficacy among undergraduate students, especially among women. Three dimensions of efficacy were used: work, career, and academic. The potential effect of co-op was controlled for a number of demographic and contextual support variables. This study was among the first to introduce the new measure of work self-efficacy. The three measures of efficacy were found to be highly reliable and valid. Among the findings, it was found that cooperative education was the single best predictor of change in work self-efficacy. However, 
while students were out on co-op - and in some cases working additional jobs - they did not increase their academic self-efficacy relative to their non-co-op counterparts. Academic advisorship was found to be critical in enhancing all forms of self-efficacy. It is the hope of the authors that this pilot study can be expanded to larger populations and become a standard that can be replicated with other populations (such as multicultural or under-represented students) or among alternative majors (such as the physical sciences).

\section{References}

[1] J. A. Raelin, R. Reisberg, D. Whitman, \& J. C. Hamann, "Cooperative Education as a Means to Enhance Self-Efficacy among Sophomores (with Particular Attention to Women) in Undergraduate Engineering," presented at the $37^{\text {th }}$ ASEE/IEEE Frontiers in Education Conference, October 10-13, 2007.

[2] Raelin, J.A., Work-Based Learning: Bridging Knowledge and Action in the Workplace. San Francisco: Jossey-Bass, 2008.

[3] Pettit, D.E., 1998 Census of Cooperative Education Executive Summary. Cooperative Education Experience, 1998.

[4] Vault.com, "More Students Interning this Summer, Says New Vault Survey," appearing in http://www.vault.com/nr/newsmain.jsp?nr_page=3\&ch_id=322\&article_id=27063890, accessed on December $12,2007$.

[5] Gardner, P. D., Nison, D. C. \& Motschenbacker, G., "Starting Salary Outcomes of Cooperative Education Graduates," Journal of Cooperative Education, 27(3), 1992, pp. 16-26.

[6] Parks, D. K., Onwuegbuzie, A. J., \& Cash, S. H., "Development of a Measure for Predicting Learning Advancement Through Cooperative Education: Reliability and Validity of the PLACE Scale," Journal of Cooperative Education, 36(1), 2001, pp. 23-31.

[7] Weston W. \& Rogers, B., "A Survey of Recent Engineering Graduates: The Relationship of Cooperative Education to Job Factors," Journal of Cooperative Education, 23(3), 1987, pp. 33-39.

[8] Eames, C., "Researching in Cooperative Education: How a Practitioner Met the Challenge!" in Linn, Miller \& Adams (Eds.), Handbook for Research in Cooperative Education and Internships, Mahwah, NJ: Lawrence Erlbaum Associates, Inc., 2003, pp. 71-94.

[9] Bandura, A., Social Foundations of Thought and Action: A Social Cognitive Theory. Englewood Cliffs, NJ: Prentice-Hall, 1986.

[10] Fletcher, J., "Self Esteem and Cooperative Education: A Theoretical Framework," Journal of Cooperative Education, 26(3), 1990, pp. 41-55.

[11] Lent, R. W., Brown, S.D., \& Hackett, G., "Toward a Unifying Social Cognitive Theory of Career and Academic Interest, Choice, and Performance," Journal of Vocational Behavior, 44, 1994, pp. 79-122.

[12] Engineering Workforce Commission of the American Association of Engineering Societies, Inc., Engineering and Technology Degrees 2005.

[13] National Science Board, Science and Engineering Indicators - 2006, Publication No. NSB-06-01.

[14] Huang, P. \& Brainard, S., "Identifying Determinants of Academic Self-Confidence Among Science, Math, Engineering, and Technology Students," Journal for Women and Minorities in Science and Engineering, 7 , 2001, pp. 315-337.

[15] Brainard, S.G. \& Carlin, L., “A Six-Year Longitudinal Study of Undergraduate Women in Engineering and Science," Journal of Engineering Education, 87(4), 1998, pp. 369-375. 
[16] Hackett, G. \& Betz, N., "A Self-Efficacy Approach to the Career Development of Women," Journal of Vocational Behavior, 18, 1981, pp. 326-339.

[17] Post-Kammer, P. \& Smith, P.L., "Sex Differences in Career Self-Efficacy, Consideration, and Interests of Eighth and Ninth Graders," Journal of Counseling Psychology, 32, 1985, pp. 551-559.

[18] Wheeler, K.G., "Comparison of Self-Efficacy and Expectancy Models of Occupational Preferences for College Males and Females," Journal of Occupational Psychology, 56, 1983, pp. 73-78.

[19] Lent, R.W., Brown, S.D. \& Larkin, K.C., "Self-Efficacy in the Prediction of Academic Performance and Perceived Career Options," Journal of Counseling Psychology, 33, 1986, pp. 265-269.

[20] Betz, N.E., Klein, K., \& Taylor, K.M., "Evaluation of a Short Form of the Career Decision-Making SelfEfficacy Scale," Journal of Career Assessment, 4, 1996, pp. 47-57.

[21] Lent, R. W., Brown, S.D., Brenner, B., Chopra, S. B., Davis, T., Talleyrand, R., \& Suthakaran, V., "The Role of Contextual Supports and Barriers in the Choice of Math/ Science Educational Options: A Test of Social Cognitive Hypotheses," Journal of Counseling Psychology, 48(4), 2001, pp. 474-483.

[22] Schlosser, L. Z., \& Gelso, C. J., "Measuring the Working Alliance in Advisor-Advisee Relationships in Graduate School," Journal of Counseling Psychology, 48, 2001, pp. 157-167. 